\title{
The Tie that Binds? A Case Study of Student Perceptions of their Recreation-related Majors
}

\author{
Karla A. Henderson \\ North Carolina State University \\ Department of Parks, Recreation, and Tourism Management \\ Box 8004 Biltmore, Raleigh, NC 27695-8004 \\ Phone: (919) 513-0352 • E-mail: karla_henderson@ncsu.edu \\ Anthony (Tony) Patterson, Ines Palacios, JungHwan (Jay) Jeon, \\ Judy Peel, Ashley (AC) Cox, Jordan Smith, and Timia Thompson \\ North Carolina State University
}

\begin{abstract}
Academic departments change to meet university and social demands. The dynamic nature of higher education leads to discourse among park and recreation educators over the unifying purpose that binds the academic field as well as practice. The purpose of this research was to use a case study at one major university to explore how undergraduate students perceived their recreation-related majors and the connections among specialty areas within the department. Analyses of focus groups along with other documents revealed four themes: learning environment, dealing with misperceptions, identification with a specialty, and connections among specializations. Students generally do not perceive connections across their academic specialties, but feel a sense of cultural commonality within the department regarding these themes. Similar to concerns raised about the fragmentation of knowledge in higher education, student perceptions reflected this phenomenon in their recreation-related majors.
\end{abstract}

KEYWORDS: Focus groups, fragmentation, learning environments, qualitative research, specializations

Note: The authors gratefully acknowledge Dr. Jason Bocarro and Dr. Candace Goode-Vick from North Carolina State University for their contributions to this project. 
Many college students begin their parks, recreation, tourism, therapeutic recreation, sports management, or outdoor recreation major (referred to hereafter as recreation-related major) with a narrow view of their academic path. These students usually have a specific career in mind such as becoming a park ranger, a recreation therapist, or an athletic director. The field of parks and recreation as defined 50 years ago has become more diversified today (Henderson, Bialeschki, Hemingway, Hodges, Kivel, \& Sessoms, 2001), and many students appear to hold a narrow view regarding their specialty (Godbey, 2000). Although specializations seem to provide students with many opportunities, they also may dilute the coherence of a professional field.

The invited papers that appeared in the 2008 volume of Schole, for example, addressed one example of professional diversity regarding the role of sport management within traditional parks and recreation departments in higher education. Dustin and Schwab (2008) argued that sport management was an uncomfortable partner for academic parks and recreation departments. Among the points made, Dustin and Schwab argued that sports management can undermine park and recreation faculty members' professional purpose. The responses to Dustin and Schwab provided counterpoints about how sport management compliments traditional park and recreation academic departments (e.g., Gibson, 2008; Howard, 2008; McDonald, 2008; Wellman \& Rea, 2008). This discussion sparked questions about the collective identity within recreation-related academic departments that often include a variety of specialized areas. Exploring further whether a collective identity exists may be useful.

Because curricula in universities have grown, we wondered how students enrolled in recreation-related specialties perceived their collective identity within a single department. Therefore, the purpose of this research was to use a case study at North Carolina State University to explore how undergraduate students perceived their recreation-related majors and the connections among specialty areas (i.e., recreation programming, tourism and commercial recreation, natural resource recreation, sport management) within the department. The results of this exploration may provide insights about the perceived identity and purpose that undergraduate students associate with the broad field of recreation. Bok (2006) argued that without a compelling unifying purpose in universities, "knowledge itself has splintered into a kaleidoscope of separate academic specialties with far too little effort to integrate the fragments, let alone show students how they might connect" (p. 2). If university communities have been indicted for this fragmentation, then exploring the integrated purpose or collective identity perceived by students in recreation-related majors within a department may be useful not only for educators but for the future of the profession.

\section{Background Literature}

As a frame for this study, we provide a short historical context about the evolution of parks and recreation curricula. In addition, we identify some of the contemporary issues facing higher education. 


\section{Historical Context}

The formal acknowledgment of a field of practice related to parks and recreation began before the turn of the 20th century. For example, in the final years of the 19th century, tracts of land were set aside for purposes of preservation and use (e.g., New York's Central Park). The enactment of the Antiquities Act of 1906 resulted in a tool for the federal government to protect public land. The Playground Association of America also began in 1906 with the purpose of advocating for the value of play for children (Hartsoe, 2006). During this same time, voluntary organizations particularly focused on youth (e.g., Girl Scouts, YMCA) grew across the U.S. With these visible recreational programs and facilities, the need for coordination and the training of leaders became apparent (Sessoms, 1993).

In the 1960s, many professional recreation and park education degree programs in higher education were established to address the anticipated need for more recreation and park professionals (Sessoms, 1993). Brightbill (1960) had "warned" that a leisure age was about to replace work in society. Professionals were needed who could guide individuals into constructive and creative uses of their leisure. At this time, the academic configurations of park and recreation programs varied across the country (Sessoms, 1993). The main association was with units of Physical Education and Health, but when a university focused more on natural resources recreation, the configuration was usually in Forestry or Natural Resources. Tourism, hospitality, and commercial recreation blossomed in the 1980s (Sessoms $\&$ Henderson, in press) with the emergence of a major focus on sports management in the early 1990s (Dustin \& Schwab, 2008).

These "newer" recreation-related areas could also be found in other academic homes such as business, human performance, rehabilitation services, and adult education. The "home" became highly dependent on the history, tradition, and politics of each university (Sessoms, 1993). The location of recreation-related specialties generally reflected the perceived demand for practitioners rather than a philosophical mission. The growth in traditional parks and recreation units in higher education that occurred in the 1960s and 1970s began to decline in the 1990s as the demand for professionals decreased and the once predicted leisure society of the 21st century failed to materialize (Sessoms). Areas such as tourism and sports seemed to have great appeal to students and offered new opportunities for employment.

The names of academic departments addressing aspects of recreation changed over the years to reflect the changing perceptions of academicians as well as society towards the concept of leisure. A focus on parks and recreation was predominant until the 1970s, (Sessoms, 1993), but the initiation of journals such as the Journal of Leisure Research and Leisure Sciences provided what many, but not all, thought was the leisure-based knowledge foundation for parks and recreation. Some academic departments changed their name to include leisure in the title (e.g., recreation and leisure studies) and some community programs also went in that direction (e.g., leisure services). By the end of the 20th century, however, many academic departments removed "leisure" from their titles and added new programmatic and mana- 
gerial foci such as tourism and sport. This name change and further specialization implied that leisure was highly misunderstood by the public. These struggles with the name seemed to reflect a broader concern with how any professional field or academic unit should be understood and perceived by the public, potential students, and university administrators (Bok, 2006).

\section{Recreation-Related Issues in Higher Education}

A concern in higher education in general is how much specialization is necessary and how much is too much, especially for a rapidly changing world where jobs that exist today may not be relevant in the future (Bok, 2006). This concern also can be raised about specialties in recreation-related areas. Does the fragmentation of knowledge due to specialization leave students with an abundance of information and no clue how to put it all together? Are students so specialized that they do not see the mission of recreation as a human service? What are the connections and are they important? In today's world, are students done a disservice if they are technically prepared for a single field and have no idea how that information can be applied in a broader sense? Another question for all academic disciplines is whether students are at a disadvantage if they are prepared for an entry level career but insufficiently educated for a future that promises great social and technological change?

The discourse in the 2008 Schole journal highlighted the debate about the connections and misperceptions about the relationships between sports management and traditional recreation programs, specifically. Dustin and Schwab (2008) argued that sport management programs undermine the traditional mission of parks and recreation programs focused on human services. They contended that if sport management is only defined relative to entertainment for spectators, it may be problematic for traditional parks and recreation organizations that are mainly concerned with participation in programs and facilitating the use of parks for many activities. In a rebuttal to Dustin and Schwab, other authors (e.g., Gibson, 2008; Howard, 2008; McDonald, 2008; Wellman \& Rea, 2008) countered that opportunities for positive associations between these specialty areas exist if departments are clear about what these specialties contribute to the overall mission of a department or a university. Although the sport management issue seems to be the topic de jour, similar concerns have been raised and not completely resolved, about how tourism fits (Ellis \& Rossman, 2008) and even how a clinical approach to therapeutic recreation has relevance to other recreation-related specialties.

Ellis and Rossman (2008) argued that "this apparent fragmentation reflects the absence of a coherent social calling that points to the need for higher education in parks, recreation, and tourism" (p. 16). They advocated that although the features of the "industries" (e.g., sport, event planning, tourism) differ dramatically, the connection is that "all are fundamentally in the business of staging quality experiences that are valued by guests, participants, clients, patients, or students"(p. 16). Sylvester (2008), however, countered that this calling falls short of how recreation-related professions should coalesce around the "well-rounded concept 
of body, mind, spirit, and community" (p. 31), similar to what Dustin and Schwab (2008) suggested. A broader question is how recreation-related professions make contributions collectively to society, and second related to our study, how students perceive their recreation-related majors and the connections among specialty areas that may contribute to the department's and college's mission as well as a greater social calling. We believe these challenges require critical examination within individual recreation-related higher education units as well as by the larger profession

\section{Method}

The design of the case study aimed to understand how students in recreation-related majors perceived the connections among specialty areas within a department. The analysis was predicated on critical theory (Henderson, 2006, Kreber, 2005) as a working framework to enable us to move beyond the status quo within the departmental unit. Critical theory enabled us to use descriptions to begin to ask questions of why the situation is as it is and how it could or should be (Kreber). We were aware of the political implications of the questions raised (Wuthnow, Hunter, Bergesen, \& Kurzweil, 1984). An understanding of recreation-related majors has not necessarily been inclusive of the areas represented, and little has been written about how the goals and purposes of these majors have been negotiated. The lens of critical theory enabled us as researchers to be explanatory and practical in addressing the existing social reality. Our case study was intended to invoke further questioning about assumptions regarding the "way things are."

A case study was an appropriate way to begin to explore the current situation at North Carolina State University and possible implications for other institutions. We used this method to gather data from document analysis, and from undergraduate students through focus groups. The unit of analysis was the Department of Parks, Recreation, and Tourism Management as interpreted through the interviews with undergraduates and the experiences of the researchers at this institution. Although we offer suggestions that may be worthy of exploration by other recreation-related higher education departments, the study is not designed to compare to other universities or to generalize beyond possible theoretical interpretations.

\section{Department Context}

The history of the department at North Carolina State University (NCSU) both paralleled, and sometimes diverged, from the history of the field as a whole. NCSU is a land-grant university created to change the landscape of higher education in North Carolina by serving children from working class backgrounds. Founded in 1862, the university focused on applied science and practical technology. In 1947, as the educational mission expanded, the Department of Industrial and Rural Recreation was established in the School of Education to prepare students to provide recreation services (NCSU, 1998). 
A physical education professor recognized that the state had a growing industrial presence largely in rural areas, and professionals were needed to address recreation desires.

The early curriculum in recreation at NCSU transitioned from a focus mainly on face-to-face leadership to an emphasis on management (NCSU, 1998). Over a ten year period, the scope of the department expanded to include environmental issues and outdoor recreation. These changes led to a new departmental name of Recreation and Park Administration in 1958 that remained housed in the College of Education. However, with growing interest in the environment and natural resources, the College of Forestry was a more compatible home, and the department was moved to the School of Forestry in 1967.

Like the profession as a whole, tourism began to blossom in the department in the 1980s. As a result, in 1989 the departmental name was changed to Parks, Recreation and Tourism Management (PRTM) to reflect the growth in tourism. Recreation programming and recreation resource management also became concentrations within the major of PRTM. In 1996, sport management was added as another concentration and in 2001 the Professional Golf Management (PGM) degree was added. As student interest in sport management continued to grow, the sport management concentration became a separate Bachelor of Science degree (i.e., Sports Management; SM) in 2005. Thus, at the time of this study the department offered three degrees in PRTM, SM, and PGM. In addition, the PRTM degree major was divided into three concentrations: park and natural resource recreation, program management, and tourism and commercial recreation. Thus, three degrees were offered that included five specialty areas.

Researchers

Researchers for this study were doctoral students and faculty in the PRTM Department at NCSU. Researchers were enrolled in or auditing a special topics class entitled, "Qualitative Research Approaches." The research team used this case study as an opportunity to gain experience in qualitative data management and to provide information to the department for an ongoing discussion about the emerging mission of the unit. The class consisted of six students either in their first or second year in the doctoral program, a faculty member auditing the class, and the instructor of record who had experience in conducting studies using qualitative research approaches. All but two researchers had at least one degree (i.e., bachelors or masters) in a recreation-related field. Our specialty interests included: natural resources (2), tourism (1), programming/ leisure behavior (2), and sport management (3). All members of the research team participated in data collection as well as made various contributions to the data analysis, interpretation, and manuscript writing. 
Researchers examined historical documents about the department, minutes of faculty retreats during the past five years, university websites, and also attended department committee meetings where issues about curriculum development were addressed. These documents and auxiliary meetings provided a context for the primary data collection discussions with students through focus groups, which are described below. The documents had been developed by the faculty but one element that was missing from the discourse about the future of the department was the "voices" of undergraduate students.

\section{Focus Group Participants}

After Institutional Review Board approval, the research team conducted focus groups over a period of three months during the fall of 2008. Undergraduate participants in the focus groups for this case study were enrolled in two required recreation courses for PRTM and SM majors. These courses were selected for the sample since they included students who had been in the department for at least a year, and thus, were assumed to have some sense of the department and the college. The instructor of record for these courses assisted with recruiting students to participate in the focus groups. Students were asked to voluntarily participate, and they were informed that a decision about participation would have no impact on their grades.

Participants from the PRTM and SM majors were represented in the focus groups. Each of the three specializations within the PRTM major was also represented. No PGM students were involved because they had few required courses with the other majors. The 30 participants included 20 males and 10 females, which represented the gender make-up of students in the department. The sample consisted of two individuals from the Park and Natural Resource Recreation concentration, 12 from the Program Management concentration, seven from the Tourism and Commercial Recreation concentration, seven from the SM major, and two that did not provide their concentration but were in the PRTM major.

Data Collection

Data from undergraduate students were collected during five focus groups with two to three researchers involved in each group. The focus groups consisted of 4-8 undergraduate students and lasted between 30 and 70 minutes. The first round of focus groups was conducted with students who had been in the major for at least one year but were just now taking the introductory course for a variety of reasons. The second round of focus groups was conducted two weeks later with students enrolled in the internship orientation class.

The first three focus groups were conducted simultaneously. After meeting the students in the classroom and offering the opportunity to participate, all students who agreed were divided into the three groups. An interview guide was developed to inquire about perceptions of the students' major. An inter- 
view guide approach is designed to elicit conversations but specifies no protocol for asking the questions. The guide allows for expanding and contracting questions and prompts during the interviews (Henderson, 2006). Because an interview guide allows for evolution of the questions, no pilot testing was undertaken although the researchers did practice using the guide and adding prompts. Examples of the interview guide questions included:

- How did you learn about the PRTM program at this university?

- When you tell your friends or family that you are majoring in PRTM or SM at NCSU, how do they respond?

- How would you assess the value of the education you are receiving?

- Explain your perception of the relationship among the various majors and concentrations within the PRTM Department. What do you think are the common denominators?

In addition to your major or concentration, how much do you know about the other majors and concentrations in the PRTM Department?

Following verbatim transcription of the first focus groups, we reviewed all records, discussed possible open codes, and assessed how the data were contributing to an understanding of the study purpose to explore how undergraduate students perceived their recreation-related major and the connections among specialty areas. Considerable information about why students chose this major was evident, but participants provided little insight about the relationships among the majors and areas of specialty. The interview guide was, therefore, revised to ask additional questions about students' perceptions of the department's mission, appropriateness of the location of the department in the College of Natural Resources, and more directly, how they saw the relationship among the different specialty areas within the department. For example, students were provided with a written list of the department's three majors and PRTM concentrations as well as the Department and the College mission statements. This information was provided to the students so they better understood the information we were seeking related to our research question. Two weeks after the first round of focus groups, the research team conducted two more focus groups with juniors and seniors who volunteered from a different class using the revised interview guide. These interviews were also transcribed verbatim.

Data Analysis

The transcriptions were reviewed for accuracy and completeness and loaded into s.ti , a computer software program used to manage and code qualitative data $\overline{\bar{r} \pi \mathrm{r}}$ transcript from one focus group was open coded by three of the primary researchers to begin the systematic data analysis process. Memos were created to help organize the emerging themes. After discussion, additional open codes were created as needed. The open codes were then grouped into axial codes to uncover possible themes. After coding transcripts, the research team used constant comparison techniques for further data analysis comparing thoughts and perceptions 
referenced in the five focus groups with each other on an incident by incident basis (Corbin \& Strauss, 2008; Henderson, 2006).

One of the challenges we faced with coding and eventual thematic descriptions was to understand what was underlying some of the responses we gathered during our focus groups. For example, recreation as a major has often been misunderstood by the public and the students' explanation of that phenomenon was not new. Our task was to examine the broader meanings that students attributed to the situation. Further, as noted in the findings section, a huge silence fell upon the groups when they were invited to tell us what they saw as the relationships among the various specialty areas. Although a discussion eventually ensued, the silence was important data to consider. We aimed to try to understand the perceptions of students about their major in our department by applying a critical perspective. Further, we focused on the trustworthiness of our process by the extensive use and sharing of memos, regular meetings to discuss our process, drawing on our own experiences as undergraduates in different universities, and using thick description to illustrate our findings.

\section{Findings}

As the data were analyzed, we looked for emerging themes about students' perceptions of their recreation-related majors and the connections among specialty areas within the department. The following four themes provided a foundation for addressing the research question: learning environment, dealing with misperceptions, identification with a specialty, and connections among specializations. These themes summarized how students perceived their major and the connections between specialty areas in the PRTM Department. The themes also led to theorizing about the academic as well as the cultural connections the students described regarding their recreation-related majors.

\section{Learning Environment}

The department's learning environment was perceived as a contributing aspect to their academic development. Students, regardless of specialty area, generally indicated that they were happy and satisfied with their recreation-related major. For example, one tourism concentration student explained:

I didn't like business. It was not the way I wanted to go. The people in the College of Management are very stuck up ... they seem very stuffy and it was a very uncomfortable environment for me. Being in PRTM everybody is more friendly [sic], easy going, and I like the way classes are structured and all the hands-on [projects]...just more like how I operate. Business wasn't offering that to me.

The culture of the department was regarded by students as relaxed and supportive. Participants felt the faculty were approachable and assisted them with their academic success. In addition, focus group participants felt other students also recognized the positive climate. A recreation programming participant stated, "I had a friend drop something off [at the department office] and ... she was amazed that people were so friendly. It's just a very friendly atmosphere." Similar feelings were expressed when participants talked about group work in classes and 
the advantages of having multiple courses with the same people. Students felt that their peers, especially within their specialization, were supportive as opposed to competitive. "You know, you have somebody in class. You don't feel alone and you know if you miss class then someone can help" stated a recreation programming participant who talked about her peers.

The classroom environment, however, was where the majority of student interaction and support occurred according to most participants. Other than in class and through group assignments, students said they generally did not have outside opportunities to network with peers. As a caveat to this observation, the department had just initiated a Sport and Recreation Club (i.e., no club for all majors had existed for some time) that the participants felt might facilitate possibilities for additional interactions. While some participants did not fully understand the purpose of the new club, others saw it as an opportunity for social and educational experiences outside the classroom. An SM participant stated:

I think [the Sport and Recreation Club] is a good way to find out about some stuff that's going on in the community. I know there's already a seminar coming up soon that they discussed about going to as a group and I think it's a good idea especially to get to know other people.

Students perceived coursework, regardless of their specialty, as useful and especially valued the practical assignments embedded in the curriculum. Students felt their majors were preparing them for a variety of jobs or admission to graduate school. They looked forward to the opportunity to apply their knowledge in real world situations. A tourism and commercial recreation participant described the practical application by stating, "We're actually going out and getting experience and excelling in a different way than just on paper." Students appreciated that they were required to participate in an internship and complete volunteer hours. One student stated:

My background is engineering and in that program the classes are very theory based. You learn and learn, [but] you don't have much practice in doing it. . . . As soon as I switched over to sport management it became very evident that sport management, especially [because of the] professors in the classes here... is much more career oriented. You learn at the same time but it's always with an end goal of this is what you will be doing.

Dealing with Misperceptions

Regardless of specialty area, students said they were accustomed to dealing with common misperceptions about a recreation-related major such as lack of academic rigor and overall value to society. Students reported that family members, friends, and even other faculty in the university did not realize the rigor involved in their major and did not see the value of a recreation-related degree.

When students told others that they were in the PRTM Department, the initial response was usually one of confusion from family or friends. One SM student stated "I think at first, my parents were like what are you going to do with that and what kind of job are you going to have with that?" Students felt they had to defend 
and explain not only their major or career choice to others but also the academic rigor of their major. A programming student stated:

Most people think it is a joke because you are going to provide pleasure for others. My boyfriend thinks it is an unstable area because he is an engineer. That's the way they think. I'm just like you stick with your numbers and your geek stuff.

Students also felt they had opportunities to challenge themselves during their service learning requirements or by completing undergraduate research with faculty as indicated by this statement:

This major can be really easy but you can choose to do research projects or choose the more difficult things, you know. You can challenge yourself and the instructors respond well to wanting more challenge.

Participants in the focus groups said they did not let the opinion of others stop them from pursuing the major they had chosen. One recreation programming major explained, "It doesn't bother me that much because I know what I want to do. Some [people] may not find this interesting but I know the best way for me to get where I want to go is through this major regardless of what people think.” The students indicated they were confident about their choice in a major and remained positive about their specialization even though they understood the misperceptions outsiders sometimes had. Most students knew this program was what they needed to find the type of job they wanted after graduation.

Identification with a Specialty

Another area of student perceptions related to their identification with their specialization. Five specialty areas were available when students applied for admission to the department and each had slightly different eligibility requirements. Most participants seemed to identify with their specialization rather than more broadly with the department. Most students had specific career goals related to their specialization (e.g., youth worker, event planner, athletic director). When participants were asked what their major was they generally answered with the name of their specialization or the type of job they wanted after graduation. For example, a recreation programming student responded to the question of "what is your major?" by saying:

I'd like to do something public like work with a parks and recreation department...I'd like to work with youth. I want to do youth programs, either youth events or even with youth sport leagues like little league or Pop Warner.

A tourism participant stated laughingly "I tell people I am in Global Economic Management." He said he uses this phrase in part because that is how he views his area of interests within tourism. Stating his major this way also avoided the jokes and comments that generally followed when he told someone he was a Parks, Recreation and Tourism Management major.

Several students who reported that family and friends were not initially supportive of their decision to pursue a degree in the department indicated that they used the specialty label to avoid stereotyped comments. For example, one student noted: 
I tell people what my major is and they are like, "Parks and Recreation, what are you going to be a gym teacher?" [I say] it's event management working with a sports team. As soon as I tell them that they say "oh we want tickets." So basically, I just tell people my major is program management because it is a little bit easier just to say that instead of saying Parks, Recreation and Tourism.

Most of the students interviewed had clear career goals, which further reinforced their identification with the specialty. Some of these students were already working in their chosen fields. One student explained:

I'd like to end up running kids' sports leagues for the city. I think program management is pretty good for that and right now in one of our classes we are actually doing stuff in the field. [We are] planning programs for our different service learning sites and we're doing programs for kids, so I think that's working out well.

\section{Connections among Specializations}

Although many students had career goals related to their specialty, most participants were not able to describe a connection among the five specialties within the department. When asked how the majors and concentrations in the department were connected, participants appeared to struggle to find a common denominator or tie for the various programs. Although students generally were talkative and forthcoming in the focus groups, the question about connections or commonalities resulted in long silences especially in the first round of interviews. Students did not have much understanding of the department and its specialties. In the second set of focus groups, students were provided with initial information about the college and department missions as well as an explanation of the specialty areas. Even with that information, students did not seem confident in discussing the connections.

Many participants could not articulate any substantive relationship among the specialties in the department. Some participants sounded confused about why this question was being asked or did not see that a connection was needed. One student stated directly, "I don't know if they really are linked together." Similarly another participant from recreation programming stated "I kind of feel like sport and program management aren't even really part of the PRTM. I don't know, I just feel like they are separate."

Students noted that they had few courses that they took together and this separation may have led to their lack of knowing about or understanding the department. Although all PRTM and SM students have four common courses, a recreation programming participant surmised, "I think it's kind of hard because as a program person I don't really have a whole lot of classes with PGM or SM people so I don't really know the different types of classes they're taking."

Rather than describe why the specialties were together in the same department, a natural resource recreation student joked "they needed to put them all somewhere." Although the student said he was just being humorous, the sentiments regarding the specialties expressed by the majority of students appeared to show a lack of knowledge and understanding of the commonalities among the specialty areas for the majority of the students. 
On the other hand, several students did see relationships across the five specializations. These students also represented all the specialties and noted that management and leadership development concepts might connect the department. "Having management type skills and being able to be a leader, being in front of the group and being able to get the group to go in whatever direction they need to go" is what one recreation programming student felt connected all the specializations. This student noted that although management and leadership development might connect all the specialties in the department, the specialties did not belong in a College of Management. A SM participant stated, "I think [the College of Natural Resources is] a better fit than going to a college of management.... I feel more comfortable working with the idea of being outdoors or being physically active or being in a sport environment." However, several students in SM did feel that they should be in a business school because "thinking about management in the PRTM Department" was different from the business school approach.

Some participants in the focus groups thought the use of natural resources and the concept of facilitating activity during peoples' leisure time were common bonds that connected the specializations. One student had this insight:

Every major uses natural resources in some way. There is no way you can do sport management without natural resources...it's all about land management.... [PRTM] definitely works well with [the College of Natural Resources] because the people that are in the other degrees in natural resources whether it's the forestry or wood and paper science they all have the same motivations and the same end goals. Not specifically to manage a sport or manage the parks recreation program, but being up here I feel everybody fits in...that everybody's going to use natural resources in some form or fashion.... I don't know if there's a better place that [PRTM] would fit.

Students who saw a common denominator among the department's specializations were able to see the potential future impacts of working closely with other students from other specializations. One recreation programming student felt gaining a broad knowledge of the department was important,

You never really know where you are going to go. You think you know what you are interested in but really the goal whenever you get out of college is to find a job and it might not be your ideal job. So I mean having a broad knowledge of the whole subject area would be good because you never really know what your first job is going to be and it probably won't be your dream job.

One student was not only able to see what bound the department together but what connections might also be made professionally:

I think later [in our careers] people that graduate from all these concentrations will be able to collaborate with each other later on down the road as colleagues. Along with a lot of other colleges here at the university PRTM should try to do more work with the Design School and Engineering because it all links together in some way.

Of the four themes that emerged, the issue of connections seemed to result in the most disparate views among the students. Although the learning environment, 
a shared knowledge of the misconceptions, and identity with a specialty were relatively consistent, the discussion about connections raised the most ambiguity for the students. Commonalities related to the culture of the department (i.e., learning environment, misunderstandings of the major) were evident but the academic connections (i.e., identity with a specialty) were not obvious to the students.

\section{Discussion}

The purpose of this research was to use a case study at NCSU to explore how undergraduate students perceived their recreation-related majors and the connections among specialty areas within the department. This case study revealed some information that might be considered by other faculty in the field of recreation regarding the understanding of an academic identity. With a base knowledge of the department's history and recent discussions by the faculty for strategic planning, the focus groups were the axis for this study. The analysis of the focus groups resulted in some unanticipated and insightful reflections on both negative and positive aspects of the departmental environment and the specialties offered. The framing of this study with a critical approach enabled us to move beyond the obvious descriptions to try to examine more deeply what the perceptions might mean for the future of our department and perhaps for other universities that might be addressing the fragmentation of recreation-related majors.

In theorizing about these data through integrating the themes, we concluded that a cultural connection existed among the students in the department, but that an academic connection generally was not shared. Regardless of specialty, students felt they experienced common learning environments (e.g., supportive faculty, practical experiences) that were helpful. Although some students appreciated the greater mission of the department, many students saw only their specific career interest. Our results highlighted the often lamented concern about the fragmentation of knowledge and the "silo" effect of universities (Bok, 2006). These findings further reflected what Buchbinder et al. described as "silos within silos" (p. 258).

The sense of a cultural connection was important to the students. Strange (2000) suggested that programs, policies, cultures, and experiences all contribute to the college environment. Students felt they shared a common culture and bond in the lack of understanding of their majors, regardless of the specialty. Further, almost all students took pride in their majors in spite of perceptions that their fields were sometimes trivialized. They felt supported in their major by other students and the department's faculty. Students also acknowledged that their major was preparing them for specific jobs and uniformly appreciated the "hands on" experiences they were getting through volunteer and internship requirements. In other words, students seemed to feel they were having a common and mostly positive educational experience within the department.

Our interest in this project, however, related to how the students in the recreation-related specialties also viewed academic and philosophical connections. Although some students had a grasp of what the department's academic mission was, most did not. Most participants in the focus groups had difficulty articulating 
a discu $\equiv$ academic identity because they were focused on their career goals. This lack of ukarerstanding seemed to reflect their perception of the department as a place for job training and not necessarily for higher education, which is a criticism about higher education today. For example, Bok (2006) stated, "The question, then, is not whether to banish all vocational courses but whether to join in giving students a larger view of the professions that goes beyond mere skills training" (p. 283).

The student views echoed the disciplinary fragmentation and specialization that exists in many aspects of higher education (Bok, 2006; Buchbinder et al., 2005). We do not believe these findings are unique only to NCSU. Some of the undergraduate student responses confirmed Dustin and Schwab's (2008) notion that sport management and parks and recreation are really in separate "nests." Godbey (2000) lamented that in the future, fragmentation within academic disciplines and departments can result in territorialism and competition that results in greater loyalty to specialties than to academic departments or to broad fields of study. Ellis and Rossman (2008) echoed this concern and stated that, "The absence of coherence places the future of such programs [parks, recreation, and tourism] at great risk" (p. 16). Dustin and Schwab also suggested that too much focus on a specialization may lead to a loss of identity regarding the purpose of these recreation-related fields. Students may not see how their specific interest fits into concern for a larger social issue like how people use their leisure or, as Ellis and Rossman suggested, how all the specialties relate to staging quality experiences.

This case study raised many questions. From the standpoint of most students, the cultural connections they had to one another were more salient than the academic connections. If faculty listened to most students, they would focus their efforts solely on vocational training and not on integrating information to address the social calling of the field. Recreation-related departments, however, may be farther along in achieving a balance between vocational training and broader educational goals. According to Buchbinder et al. (2005), the internships and work experiences provided in any curriculum may be giving students interdisciplinary teamwork skills that they do not recognize. Nevertheless, how important the common identity is to a department or to a field of study requires more study and reflection. A number of academic implications can be considered.

\section{Academic Implications}

From this case study, we offer several suggestions for our university that might be important for other recreation-related units in higher education. First, recreation-related faculty may also want to further consider a collective identity or an agreed upon understanding of the connections in the diverse recreation-related areas. If faculty do not see the commonalities across specialties, then students may be less likely to see them. Ironically, most faculty members are encouraged to have a great depth of knowledge about a specialty so their research reflects a profound understanding of one area. Faculty may be graduating from universities with much more depth than breadth in understanding the recreation field. Further, graduate experiences of faculty may be from a department or college that did not 
have the same specialties as their current faculty post. Godbey (2000) described how overspecialization is also evident in the specialized journals and conferences that further separate faculty. Regardless, faculty perceptions may set the stage for what students believe is important. Perhaps faculty members need to revisit their mission from time to time as well as the mission of their college and institution to assure that the curriculum reflects a "common calling."

Second, faculty in a recreation-related department may also examine their curricula to determine what core coursework is needed regardless of specialty. Students sometimes do not see why they have to take "generic" classes in a department, which puts the onus on faculty to use a variety of examples and show the connections among specialties as part of the foci of the coursework. The design of courses with group work could also be a way to increase the networking and understanding among students. Some universities have found that a Senior Seminar or capstone course focused on common issues (e.g., ethics, sustainable communities, professional expectations, diversity) may be useful in helping students see the interdisciplinary aspects of their fields of study.

In addition, a department might want to facilitate the success of a majors club that can encourage the students from all specialties to participate together in social as well as common professional activities. Club activities may promote positive interaction among students since the students seem to recognize the benefits of active exchange with other students.

We believe this case study is meaningful because we built on existing department discussions to include students' perceptions of their recreation-related majors. We listened to their "voices." The study, however, has a few limitations. First, we only investigated the students at one land grant university. Currently over 300 institutions are offering parks, recreation and leisure related majors in the U.S. Not all schools may be facing the same issues as those faced in this case study. Nevertheless, we believe the issues are not uncommon. Second, the findings of this study are also limited because there were no participants from the Professional Golf Management (PGM) major. Even though only a few parks and recreation curricula offer a PGM major and less than $10 \%$ of the students in the department are in the PGM program, their input may have been useful. Their curriculum, however, is quite different than the other specialties in the department. Students in the focus groups did talk about the PGM major, so insight was gathered from their perspective.

Nevertheless, this case study illuminated from students' perspectives as well as document analysis some of the concerns that had been expressed by faculty in our university. The study provided information that will be useful to us and we hope the analysis will spark further discussion about curricula in other universities. Although philosophically the need to be more interdisciplinary in universities seems to be regularly discussed (Bok, 2006), perhaps individual units need to also consider how to create interdisciplinary interaction in the silos within the silos (Buchbinder et al., 2005). Having cultural commonalities are important in a unit in providing students with positive learning environments. From the standpoint 
of delivering a "higher education" for today's students, however, understanding the collective identity of an academic field of study as well as the social calling is important and valuable.

\section{References}

Bok, D. C. (2006). Our underachieving colleges: A candid look at how much students learn and why they should be learning more: Princeton University Press.

Brightbill, C. K. (1960). The challenge of leisure. Englewood Cliffs, NJ: Prentice-Hall.

Buchbinder, S., Alt, P., Eskow, K., Forbes, W., Hester, E., Struck, M., et al. (2005). Creating learning prisms with an interdisciplinary case study workshop. Innovative Higher Education, 29(4), 257-274.

Corbin, J. M., \& Strauss, A. L. (2008). Basics of qualitative research: Techniques and procedures for developing grounded theory (3rd edition.). Thousand Oaks, CA: Sage Publications Ltd.

Dustin, D. L., \& Schwab, K. A. (2008). Consider the Kirtland's Warbler. Schole, 23, 1-8.

Ellis, G. D., \& Rossman, J. R. (2008). Creating value for participants through experience staging: Parks, recreation, and tourism in the experience industry. Journal of Park and Recreation Administration, 26(4), 1-20.

Gibson, H. (2008). Comment on Dustin and Schwab article, "Consider the Kirtland's Warbler". Schole, 23, 17-20.

Godbey, G. (2000). The future of leisure studies. Journal of Leisure Research, 32(1), 37-41.

Hartsoe, C. E. (2006). Building better communities: The story of the National Recreation Association (1906-1965). Champaign, IL: Sagamore Publishing.

Henderson, K. A. (2006). Dimensions of choice: Qualitative approaches to parks, recreation, tourism, sport and leisure research (2nd edition.). State College, PA: Venture Publishing.

Henderson, K. A., Bialeschki, M. D., Hemingway, J. L., Hodges, J. S., Kivel, B. D., \& Sessoms, H. D. (2001). Introduction to recreation and leisure services (8th edition.). State College, PA: Venture Publishing.

Howard, D. (2008). Comment on Dustin and Schwab article, "Consider the Kirtland's Warbler". Schole, 23, 13-16.

Kreber, C. (2005). Charting a critical course on the scholarship of university teaching movement. Studies in Higher Education, 30(4), 389-405.

McDonald, C. (2008). Comment on Dustin and Schwab article, "Consider the Kirtland's Warbler". Schole, 23, 21-22.

North Carolina State University. (1998). A 50 year salute: The Department of Parks, Recreation and Tourism Management. Raleigh, NC: Author.

Sessoms, H. D. (1993). Eight decades of leadership development: A history of programs of professional preparation in parks and recreation 1909-1989. Arlington, VA: National Recreation and Park Association.

Sessoms, H. D., \& Henderson, K. A. (in press). The noble experiment: A history of the National Recreation and Park Association, 1966-2005. Ashburn, VA: National Recreation and Park Association.

Strange, C. C. (2000). Dynamics of campus environments. In M. J. Barr \& M. K. Desler (Eds.), The handbook of student affairs administration (2nd edition, pp. 297-316). San Francisco, CA: Jossey-Bass.

Sylvester, C. (2008). The ethics of experience in recreation and leisure services. Journal of Park and Recreation Administration, 26(4), 21-41.

Wellman, J. D., \& Rea, P. S. (2008). Comment on Dustin and Schwab article, "Consider the Kirtland's Warbler". Schole, 23, 9-12.

Wuthnow, R., Hunter, J. D., Bergesen, A., \& Kurzweil, E. (1984). Cultural analysis. London: Routledge and Kegan Paul. 